\title{
Occurrence of Viral Infection in Haemodialysed CKD Cases in Libya
}

\author{
Khaled M. D ${ }^{1}$, A. Faiz ${ }^{2}$, A. T. Abdelgader ${ }^{3}$, S. Bioprabhu ${ }^{4}$ \\ ${ }^{1}$ Academy of Graduate Studies, Tripoli, Libya \\ ${ }^{2,3}$ Department of Urology, Faculty of Medicine, Al-khoms, Libya \\ ${ }^{4}$ Department of Microbiology, Faculty of Medicine, Al-khoms, Libya
}

\begin{abstract}
Chronic Kidney Disease (CKD) is a serious condition of loss of renal function progressively occurs usually within a course of several years. It is increasing rapidly worldwide at an annual growth rate of $8 \%$. The prevalence of CKD is higher in developing countries than the developed countries are alarming and has become a major health issue. Haemodialysis patients are particularly predisposed to infections. The study is planned to assess the occurrence of different viral infection in CKD patients of PreHaemodialysis and Post Haemodialysis patients at Al-khoms teaching hospital, Al-khoms, Libya. Total of 71 (42 male and 29 female) cases of CKD with HD are included in the study. Blood samples are collected and centrifuged to take serum. Incidence of different viral infections are analysed from the serum of CKD patients after HD using ELISA technique. Generally viral infections are more in HD and transplant cases. But in this study no HIV is reported and few cases of HBV and HCV are found out. So prevention measures should be adopted to reduce or completely prevent these infections.
\end{abstract}

Keywords: Haemodyalysis, Viral infection, CKD, Libya

\section{Introduction}

Chronic kidney disease $(\mathrm{CKD})$ is a disease that has been present for months to years. Chronic renal disease (CRD), chronic renal failure (CRF), and chronic renal insufficiency refer to the same condition. CKD is not a single disease. When an individual has a diagnosis of CKD, there is nephron dysfunction that persists three months or longer resulting in irreversible kidney damage. More often kidney function worsens over a number of years. By the time the signs of CKD revealed, the damage is severe. There is no cure for CKD. The remaining nephrons are working so hard that with time they will fail as well. CKD is usually fatal in months to years but various treatments can keep the people comfortable and with a good quality of life for months to years. CKD epidemiology shows more in the developing countries than in the developed one. An incidence of CKD increases with age (Iseki et al., 1993). Patients with renal failure are susceptible to infection. In the predialysis era, $60 \%$ of patients with chronic renal failure requiring hospitalization were infected and $39 \%$ died from infectious causes. It was assumed that the debility caused by the uremic state increased the risk of infection, and the reversal of uremia would reduce the risk of infection (Berman, 2004).

Haemodialysis (HD) is a medical procedure to filter the wastes from the blood and to retain the normal constituents of the blood by a special dialysis machine. HD is frequently done with end stage of chronic renal failure. HD procedure disturbances in both innate (Muniz-Junqueira et al.,2005 and Eleftheriadi et al., 2008) and adaptive immunity (Eleftheriadis et al., 2008) make HD patients susceptible to infections. Infections are the major cause of morbidity and the second cause of death following cardiovascular events in HD patients.
People with CKD may be more susceptible to infection. It is recommended that they get the vaccinations for Hepatitis $\mathrm{B}$ and A, Influenza, H1N1 (swine flu), HIV and Some Bacteria like Pneumococcus. Worldwide, about 170 million people are infected by the hepatitis $\mathrm{C}$ virus (HCV). Infection is much more common in patients with chronic kidney disease (CKD) than in the general population. Infection with the hepatitis $\mathrm{C}$ virus (HCV) is an unsolved public health problem. One reason for this is that infection with HCV can cause kidney disease. Another reason is that the virus is transmitted through contact with blood and can be passed between patients in dialysis units if the correct hygienic precautions are not followed. Before it was possible to screen for HCV, many CKD patients were infected through blood transfusions (KDIGO, 2009). In Europe its incidence ranges from $0.2 \%$ to $3.5 \%$ (Esteban et al., 2008). Cavoli et al., (2011) explained the Hepatitis C virus (HCV) infection is a never-ending public health problem. Many studies have investigated the incidence of $\mathrm{HCV}$ infection among dialysis patients, but there have only been a few epidemiological studies in renal conservative therapy. They studied 320 subjects with pre-dialysis chronic kidney disease living in Sicily, Italy. The incidence of HCV infection was $6.25 \%$. In Europe, incidence ranges from $0.2 \%$ to $3.5 \%$. It appears that the incidence of $\mathrm{HCV}$ infection is higher in the studied patient population than in the population as a whole.

Kidney disease is an important complication of human immunodeficiency virus (HIV) infection. Kidney function is abnormal in up to $30 \%$ of HIV-infected patients, AIDSrelated kidney disease has become a relatively common cause of end-stage renal disease (ESRD) requiring dialysis, and kidney disease may be associated with progression to AIDS and death (Gupta et al., 2004).

The aim of this study is to assess the occurrence of different viral infection in CKD patients of Haemodialysed patients at Al-khoms teaching hospital, Al-khoms, Libya. 


\section{International Journal of Science and Research (IJSR)}

ISSN (Online): 2319-7064

Index Copernicus Value (2013): 6.14 | Impact Factor (2014): 5.611

\section{Materials and Methods}

Total of 71 (42 male and 29 female) cases of CKD with HD are included in the study. Blood samples are collected after HD (Dialog+, B.Braun, USA) using sterile syringe and Vacutainer tubes and centrifuged (Heraeus Model) at 3000 rpm to take serum. Presence of HIV, HCV and HBAg's antibodies were checked with the help of ELISA Reader EL50., Germany.

\section{Results and Discussion}

Chronic Kidney Disease (CKD) is a serious condition when the loss of renal function progressively occurs usually within a course of several years. It can be caused by the factors such as cardio-vascular disease, hypertension, diabetes, and obesity among others. If untreated, it can progress to the End-Stage Renal Disease (ESRD) and dialysis treatment or kidney transplant would be needed. Patients with CKD can experience poor quality of life, increased health care expenses, and increase the risk of death.

Table 1: HIV infection levels in Male and Female of CKD patients of different ages.

\begin{tabular}{|c|c|c|c|c|c|c|c|}
\hline $\begin{array}{c}\text { S. } \\
\text { No. }\end{array}$ & Age & Nos. & \multicolumn{2}{|c|}{$\begin{array}{c}\text { Male } \\
\text { Negative Positive }\end{array}$} & Nos. & \multicolumn{2}{|c|}{$\begin{array}{c}\text { Female } \\
\text { Negative Positive }\end{array}$} \\
\hline 1 & $1-20$ & 01 & 01 & 00 & 03 & 03 & 0 \\
\hline 2 & $21-40$ & 10 & 10 & 00 & 07 & 07 & 0 \\
\hline 3 & $41-60$ & 25 & 15 & 00 & 15 & 15 & 0 \\
\hline 4 & $61-80$ & 06 & 06 & 00 & 04 & 04 & 0 \\
\hline
\end{tabular}

Table 2: HBsAg infection levels in Male and Female of CKD patients of different ages

\begin{tabular}{|c|c|c|c|c|c|c|c|}
\hline $\begin{array}{c}\text { S. } \\
\text { No. }\end{array}$ & Age & Nos. & \multicolumn{2}{|c|}{ Male } & Nos. & \multicolumn{2}{c|}{$\begin{array}{c}\text { Female } \\
\text { Negative Positive }\end{array}$} \\
\hline 1 & $1-20$ & 01 & 01 & 00 & 03 & 02 & 01 \\
\hline 2 & $21-40$ & 10 & 10 & 00 & 07 & 07 & 00 \\
\hline 3 & $41-60$ & 25 & 25 & 00 & 15 & 14 & 01 \\
\hline 4 & $61-80$ & 06 & 06 & 00 & 04 & 04 & 00 \\
\hline
\end{tabular}

Table 3: HCV infection levels in Male and Female of CKD patients of different ages

\begin{tabular}{|c|c|c|c|c|c|c|c|}
\hline $\begin{array}{c}\text { S. } \\
\text { No. }\end{array}$ & Age & Nos. & \multicolumn{2}{|c|}{$\begin{array}{c}\text { Male } \\
\text { Negative Positive }\end{array}$} & Nos. & \multicolumn{2}{c|}{$\begin{array}{c}\text { Female } \\
\text { Negative Positive }\end{array}$} \\
\hline 1 & $1-20$ & 01 & 01 & 00 & 03 & 03 & 00 \\
\hline 2 & $21-40$ & 10 & 10 & 00 & 07 & 07 & 00 \\
\hline 3 & $41-60$ & 25 & 22 & 03 & 15 & 13 & 02 \\
\hline 4 & $61-80$ & 06 & 05 & 01 & 04 & 04 & 00 \\
\hline
\end{tabular}

People with CKD/ESRD may be more susceptible to infection. Result of present study revealed that there is no HIV infection (Table 1) of Haemodialysis cases in al-khoms teaching Hospital, Al-khoms. This result depicts the Life style of people in Libya. All HD patients should be tested for HIV since prompt diagnosis, monitoring and timely initiation of Highly Active Anti-Retroviral Therapy (HAART) consisted of three or more highly potent anti-HIV drugs, commonly reverse transcriptase inhibitors and protease inhibitors, improves prognosis (Vardinon et al., 1999).

HBV infections are found in 2 female cases (1 in age between 1 and 20 years and the other one in the age between 41 and 60 years old) (Table 2). Hepatitis viral infections like
HBV in Haemodialysis patients presents a distinct clinical problem in the view of immunosuppressive effect of renal failure, susceptibility to de novo infection and Nosocomial transmission (Kes and Slavicek, 2009). It is estimated that approximately 350 million people are chronic hepatitis B virus (HBV) carriers worldwide (Lavanchy, 2004). Consequently, most HD units treat chronic HBV carriers. Interestingly, because of the known acquired immunity disturbances in this population, after the initial HBV infection, $60 \%$ of haemodialysis patients become chronic carriers, while the respective percentage in the general population is only 5\% (London et al., 1977). Vaccination against $\mathrm{HBV}$ is also an effective measure, since vaccinated patients have $70 \%$ less possibility to become HBV carriers (Miller et al., 1999).

Result of HCV indicates that there are 6 positive cases from the 71 cases (Table 3). Five HCV infection patients are observed in both male ( 3 cases) and female ( 2 cases) of the same age between 41 and 60 years old (Table 3 ) and another one male case is observed in the age between 61 and 80 years old. Fabrizi et al., (2004) explained that the infection of HBV and HCV are the most common in the patients with liver disease. Gioacchino et al., (2011) also informed that $\mathrm{HCV}$ infection is a never-ending public health problem among HD patients. There are about 170 million hepatitis $C$ virus (HCV) carriers worldwide and HD patients belong to a high-risk population (Yen et al., 2003). A meta-analysis revealed that in HD patients' $\mathrm{HCV}$ carriage is associated with 1.57 times increased risk of death. Liver cirrhosis and hepatoma contribute to the increased mortality (Fabrizi et al., 2004). The routine ribavirin treatment show adverse effect. The only available treatment for HCV infection with HD patient is interferon A with more than or equal to 30,00,000 units 3times a week (Gordon et al., 2008).

\section{Conclusion}

Generally viral infections are more in HD and transplant cases. But in this study no HIV is reported and few cases of $\mathrm{HBV}$ and HCV are found out. The chances of infection of the vascular access are increased in patients with poor personal hygiene, malnutrition and inadequate dialysis. Prevention of infection is one of the few avenues available to reduce hospitalizations, control costs, and improve quality of life for these patients.

\section{References}

[1] Berman SJ, Johnson EW and Nakatsu C, (2004) Burden of infection in patients with end-stage renal disease requiring long term dialysis. Clinical Infectious Diseases. 39:1747-53.

[2] Cavoli G.L, Ferrantelli A, Bono L, Tortorici C, Giammarresi C, Zagarrigo C, Schillaci O, Trolongo A, Soresi M and U Rotolo (2011) Int. J. of Inf. Diseases. 15 (8):e514-e516.

[3] Eleftheriadis T, Kartsios C, Yiannaki E, Kazila P, Antoniadi G, and Liakopoulos V. (2008) Chronic inflammation and CD16+ natural killer cell zeta-chain downregulation in hemodialysis patients. Blood Purif. 26:317-321.

\section{Volume 4 Issue 11, November 2015}




\section{International Journal of Science and Research (IJSR) \\ ISSN (Online): 2319-7064}

Index Copernicus Value (2013): 6.14 | Impact Factor (2014): 5.611

[4] Eleftheriadis T, Kartsios C, Yiannaki E, Kazila P, Antoniadi G, and Liakopoulos V. (2008) Chronic inflammation and $\mathrm{T}$ cell zeta-chain downregulation in hemodialysis patients. Am J Nephrol. 8:152-157.

[5] Esteban, J.I., S. Sauleda and J. Quer (2008). The changing epidemiology of hepatitis $\mathrm{C}$ virus infection in Europe. J Hepatol, 48 : 148-162.

[6] Fabrizi F, Martin P, Dixit V, Bunnapradist S, and Dulai G. (2004) Meta analysis: Effect of hepatitis C virus infection on mortality in dialysis. Aliment Pharmacol Ther.20:1271-1277.

[7] Gioacchino L.C., Angelo F., Luisa B., Calogera T., Carlo G., Carmela Z., Onofrio S., Angelo T., Maurizio S and R Ugo (2011) Incidence of Hepatitis C Virus infection in patients with chronic kidney disease on conservative therapy. Intl $J$ of Infectious diseases 15:e514-e516.

[8] Gordon CE, Uhlig K, Lau J, Schmid CH, Levey AS, and Wong JB. (2008) Interferon treatment in hemodialysis patients with chronic hepatitis $\mathrm{C}$ virus infection: a systematic review of the literature and metaanalysis of treatment efficacy and harms. Am J Kidney Dis. 51:263-277.

[9] Gupta SK, Mamlin BW, Johnson CS, Dollins MD, Topf JM, Dube MP. (2004). Prevalence of proteinuria and the development of chronic kidney disease in HIV-infected patients. Clin Nephrol . 61:1-6.

[10] Iseki K., Kewazeo N., Osawa A. and Fukiyama K. (1993) Survival analysis of dialysis patients in Okinawa, Japan. Kidney inter. 43: 404-409.

[11] KDIGO (2009). www.kdigo.org.

[12] Kes P and Slavicek J. (2009) Hepatitis B virus and chronic progressive kidney disease. Acta med croatica. 63(5):397-402.

[13] Lavanchy D. (2004) Hepatitis B virus epidemiology, disease burden, treatment, and current and emerging prevention and control measures. J Viral Hepat. 11:97107.

[14]London WT, Drew JS, Lustbader ED, Werner BG, and Blumberg BS. (1977) Host responses to hepatitis B infection in patients in a chronic hemodialysis unit. Kidney Int. 12:51-58.

[15] Miller ER, Alter MJ, and Tokars JI. (1999) Protective effect of hepatitis B vaccine in chronic hemodialysis patients. Am J Kidney Dis. 33:356-360.

[16] Muniz-Junqueira MI, Braga Lopes C, Magalhaes CA, Schleicher CC, and Veiga JP. (2005) Acute and chronic influence of hemodialysis according to the membrane used on phagocytic function of neutrophils and monocytes and pro-inflammatory cytokines production in chronic renal failure patients. Life Sci.77:3141-3155.

[17] Vardinon N, Yust I, Katz O, Iaina A, Katzir Z, and Modai D. (1999) Anti-HIV indeterminate western blot in dialysis patients: a longterm follow-up. Am J Kidney Dis.34:146-149.

[18] Yen T, Keeffe EB, and Ahmed A. (2003) The epidemiology of hepatitis $\mathrm{C}$ virus infection. J Clin Gastroenterol.36:47-53. 